\title{
Evaluation of Shape and Size of Sella Turcica Using Computerized Tomography in Saudi Populations
}

Hanan Elnour ${ }^{1,2^{*}}$, Afrah Al-Otaibi ${ }^{1}$, Maryam AL-Otaibi ${ }^{1}$, Nourhan Arab ${ }^{1}$, Rahaf AL- Thobaiti ${ }^{1}$, Roaa Murad ${ }^{1}$, Sara ALOtaibi $^{1}$

${ }^{1}$ Radiological Sciences Department, College of Applied Medical Sciences, Taif University, KSA

${ }^{2}$ College of Radiological Science and Medical Imaging, Alzaaiem Alazhari University, Khartoum -Sudan

DOI: $10.36347 /$ sjams.2020.v08i09.016

| Received: 03.09.2020 | Accepted: 10.09.2020 | Published: 17.09.2020

*Corresponding author: Hanan Elnour

Abstract

This study design to measure the size and shape of normal Sella turcica, were samples chosen among individuals from adult Saudi populations aged 19-99 years. A total of 210 samples (125 males and 85 females), and the data collected in period from August 2019 to February 2020. Anteroposterior dimension, length and depth of Sella turcica were measured in each case and find out three unique shapes; the circle shape represents $40.5 \%$ with 85 patients, the ovoid shape $42.4 \%$ with 89 patients while the flat shape $17.1 \%$ with 36 patients, measurements obtained from measuring of Sella turcica, were the mean \pm standard deviation for age was $47.59 \pm 20.289$ years, length, Width, AP and volume of Sella turcica was $8.07 \pm 2.06 \mathrm{~mm}, 7.408 \pm 1.64 \mathrm{~mm}, 10.11 \pm 2.08 \mathrm{~mm}$ and $339.52 \pm 203.69 \mathrm{~mm}$ respectively. The mean length of sella turcica for male and female was 8.010 and $8.165 \mathrm{~mm}$, the Width for male was $7.215 \mathrm{~mm}$ and for female $7.692 \mathrm{~mm}$, AP diameter for male 10.050 and for female $10.193 \mathrm{~mm}$, the volume of sella turcica for male was 329.139 and for female $354.781 \mathrm{~mm}$, so there is no difference between male and females. There is linear correlation between age of study group and the measured parameters from 19- 99 years. Analysis of variance test show that there was no significant difference between the Sella measurements, for length and patients age, where the p-value was 0.285 and for Width, AP and volume the p.value was $0.222,0.128$ and 0.067 respectively. CT can be used to assess the Sella turcica, and further studies on how the dimensions of the Sella turcica are interrelated with pathological conditions should be conducted with the use of advanced imaging methods. Sella turcica dimensions of the Saudi population obtained by CT in this study can be used in estimating pituitary gland size and in determining any pathology in the seller and parasailer regions.

Keywords: Sella turcica, pituitary gland, Computed Tomography, Brain.

Copyright @ 2020: This is an open-access article distributed under the terms of the Creative Commons Attribution license which permits unrestricted use, distribution, and reproduction in any medium for non-commercial use (NonCommercial, or CC-BY-NC) provided the original author and source are credited.

\section{INTRODUCTION}

The sella turcica is an important saddle-shaped structure that houses the pituitary gland and is located in the middle cranial fossa [1]. The structure consists of anterior and posterior clinoid processes, the tuberculum sella and the pituitary fossa. The tuberculum sella is the slight anterior elevation on the body of the sphenoid bone. The pituitary fossa is a saddle-like depression in the middle that holds the pituitary gland, and the dorsum sella is formed by a square plate of bone on the body of the sphenoid [2]. Lip and palate clefts are considered the most prevalent craniofacial congenital anomaly. Some studies have been conducted on the causes of cleft, as well as on the development of craniofacial structures in people with clefts $[1,3]$. Close interactions exist during the development of the hypothalamus, pituitary gland, and oral cavity in early embryonic life $[1,4]$. Any defect in the development of these tissues may lead to anatomical and functional disorders [5]. Many studies have focused on the morphology of the sella turcica and the relationship between its dimensions and general craniofacial deviations [6-9].

The effect of deviations in the morphology of the sella turcica in individuals with clefts has been reported in several 2-dimensional cephalometric studies $[3,4,10]$. However, the 2-dimensional representation of an abnormality does not actually provide complete information about its structure [4]. Only advanced imaging techniques such as computed tomography (CT) or cone-beam (CB) CT can generate more precise information about the sellar region [4]. CBCT produces hard-tissue images of a similar quality to those of CT. However, the images are obtained with less expensive equipment and components, a reduced patient 
examination time, and a significantly lower radiation dose than with conventional CT [11].

For diagnosis of facial skeletal type and assessment of orthodontic treatments, several points in the craniofacial region of patients are used as reference points in tracing lateral cephalometry radiographs. Sella turcica is among the most important orthodontic landmarks. Sella point is of special significance due to its role as the central reference point in the assessment of cranial morphology and intermaxillary relations [12].

The various variables measured in anthropometry include; weight, height, length, widths and thickness of the various parts of the body. These indices are used for forensic analysis as well as gender, race and age determination [13]. Sella Turcica is an important anatomical structure that lies at middle cranial fossa of the skull, containing the pituitary gland. It derives its name from the comparative shape to Turkish saddle [14]. The despondency in saddle is distinguished as pituitary fossa or hypophyseal fossa while the pituitary gland is located in the fossa. Sella turcica is bounded anteriorly by tuberculum sellae, posterially by dorsum sellae and inferiorly by the bony roof of the sphenoidal air sinus [15-17]. There are 2 (two) anterior and two (2) pesterior clinoid processes. The anterior cliniod process is derived from anterior and medial projections of lesser wing of sphenoid bone, while posterior clinoid process stand for termination of dorsum sella [16, 18]. Computerized Tomographic Scan (CT Scan) on the other hand, refers to ionizing radiation that is made up of an X- rays which can be used for image reconstruction using a computer. However, CT Scan has lower radiation toxicity and more costly compared to simple radiograph $[19,20]$.

Changes in sella turcica of children are not prominent and visible as in adults. Some tumours and associated increased intracranial pressure conditions do not cause remarkable changes in sella shapes and size, unless they are chronic in nature and changes resolved rapidly with the treatment of the condition [21]. Other changes associated with pediatric sella turcica are hypertrophic and hypotrophic posterior clinoid process, oblique contour of the floor [22]. Oblique anterior wall sella has been documented in normal children and those with Seckel syndrome, lumbosacral myelomeningocoele, Down's syndrome as well as both prenatal and postnatal fragile $X$ [23]. Sella bridge appears when there is union between anterior and posterior clinoid process of the sella turcica [24, 25]. It can be classified into type $\mathrm{A}$ and type $\mathrm{B}$. Type $\mathrm{A}$ is a ribbon-like while type $\mathrm{B}$ is just a bony projection of either anterior or posterior clinoid process [26]. Sella bridge is a normal variant of sella shape and was reported by several workers.
Several studies conducted on the shape of sella turcica have concluded that the morphological appearance of the sella turcica is established in the early embryonic structure.

Profile radiographs of 16 children born with myelomeningocele revealed an altered shape of sella present during foetal life [27, 28] found, in a foetus with holoprosencephaly, that the area of the sella turcica also displayed malformations. In children with fragile $\mathrm{X}$ and Down syndrome, a change of sella shape was evident pre-natally and continued post-natally [29, 30].

\section{Methodology}

This is prospective descriptive study conducted in King Abdul-Aziz Specialist Hospital and King Faisal Specialist Hospital to determine the size and shape of Sella turcica using CT scan in relation to age and gender of individual. The subject included were chosen among individuals from adult Saudi population aged 19-99 years admitted to department of radiology for any reason and brain computed tomography (CT) scanning. A total of 210 samples (125 males and 85females) who met the inclusion criteria, were recruited and studied from August 2019 to February 2020.

\section{Equipment's and Accessories Used in Data Collection}

Two type of CT Scanner used to perform the study GE - discovery CT750 (180) detectors and GE revolution discovery (256) detectors, Radiology CT Reports, Patient's Records, Radiology Information System Software and Normal, lateral CT images

Data collection sheet was designed containing all the variables. The age and gender of the patients was taken before the CT scan. After scanning the patients, the consultant radiologists reported the examination. When the report indicates that the examination was normal, then the biometric dimensions (length, AP diameter and Width) of the Sella turcica were measured using the software measuring tools in the computers of the CT workstation

\section{Measurements Technique}

Measurements were performed using 3 parameters on sagittal section is closest to mid sagittal section. The length of the Sella turcica was measured as the distance from the tuberculum Sella to the tip of the dorsum sellae, and the Width of Sella turcica was measured perpendicular to this line to the deepest point on the floor. The anterior-posterior greatest diameter of the sella is measured to a point on the posterior inner wall of the pituitary fossa furthest from the tuberculum sellae as shown in Figure-1 below [9]. 


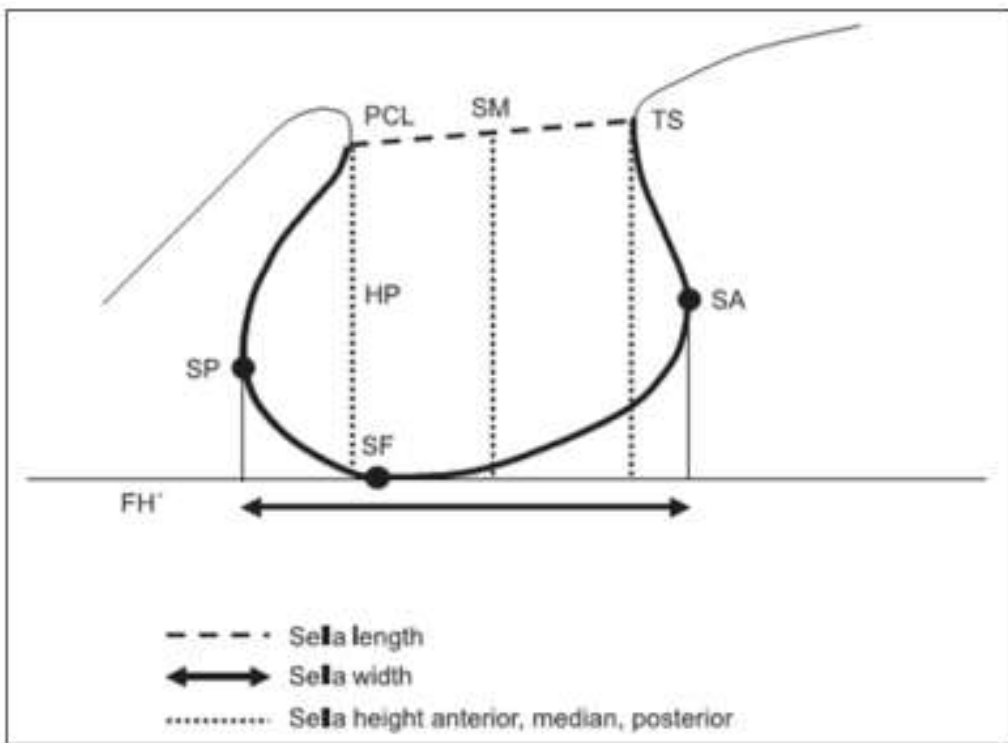

Fig-1: The following points were digitized: porion (Po) and orbitale (Or); tuberculum sella (TS), the most anterior point of the contour of the sella turcica; posterior clinoid (PClin), the most anterior point of the PClin process

Ethical consideration: Approval from the ethical committee of the College of scientific Research Center at Taif University was obtained.

\section{RESULTS}

Table-1: Show statistical parameters for all patient's variables

\begin{tabular}{|l|l|l|l|l|l|}
\hline & Mean & Median & STD & Min & Max \\
\hline Age & 47.59 & 44.50 & 20.289 & 19 & 98 \\
\hline Length & 8.07 & 8 & 2.056 & 0.8 & 15.7 \\
\hline Width & 7.408 & 7.2 & 1.64 & 0.8 & 14.7 \\
\hline AP & 10.11 & 10 & 2.08 & 4.3 & 16.9 \\
\hline Volume & 339.52 & 293.79 & 203.69 & 26.8 & 1379.7 \\
\hline
\end{tabular}

Table-2: Show age group for all patients with mean and standard deviation for each group

\begin{tabular}{|l|l|l|}
\hline Age Group & Mean of Volume & STD of volume \\
\hline Less than 19 Years & 166.28 & 32.41 \\
\hline $19-25$ Years & 279.46 & 133.73 \\
\hline $26-40$ Years & 317.80 & 149.43 \\
\hline $41-50$ Years & 363.75 & 259.36 \\
\hline More than 50 Years & 374.22 & 228.66 \\
\hline
\end{tabular}

Table-3: Show statistical parameters for measurement parameters of sella turcica according to the patients gender

\begin{tabular}{|l|l|l|l|l|l|}
\hline & Gender & $\boldsymbol{N}$ & Mean & Std. Deviation & Std. Error Mean \\
\hline \multirow{3}{*}{ Length } & Male & 125 & 8.010 & 2.1078 & .1885 \\
\cline { 2 - 6 } & Female & 85 & 8.165 & 1.9850 & .2153 \\
\hline \multirow{3}{*}{ Width } & Male & 125 & 7.215 & 1.6770 & .1500 \\
\cline { 2 - 6 } & Female & 85 & 7.692 & 1.5599 & .1692 \\
\hline \multirow{2}{*}{ Volume } & Male & 125 & 10.050 & 2.1858 & .1955 \\
\cline { 2 - 6 } & Female & 85 & 10.193 & 1.9277 & .2091 \\
\cline { 2 - 6 } & Male & 125 & 329.139 & 206.7629 & 18.4934 \\
\cline { 2 - 6 } & Female & 85 & 354.781 & 199.3108 & 21.6183 \\
\hline
\end{tabular}


Table-4: Show analysis of variance between the patients age with measurement variables of sella turcica

\begin{tabular}{|l|l|l|l|l|l|l|}
\hline \multicolumn{2}{|c|}{} & Sum of Squares & df & Mean Square & F & p.value \\
\hline LENGTH & Between Groups & 309.658 & 68 & 4.554 & 1.120 & .285 \\
\cline { 2 - 7 } & Within Groups & 573.421 & 141 & 4.067 & & \\
\cline { 2 - 7 } & Total & 883.080 & 209 & & & \\
\hline \multirow{5}{*}{ DEPTH } & Between Groups & 203.279 & 68 & 2.989 & 1.167 & .222 \\
\cline { 2 - 7 } & Within Groups & 361.317 & 141 & 2.563 & & \\
\cline { 2 - 7 } & Total & 564.596 & 209 & & & \\
\hline \multirow{5}{*}{ Volume } & Between Groups & 342.101 & 68 & 5.031 & 1.259 & .128 \\
\cline { 2 - 7 } & Within Groups & 563.547 & 141 & 3.997 & & \\
\cline { 2 - 7 } & Total & 905.648 & 209 & & & \\
\cline { 2 - 7 } & Between Groups & 3427935.340 & 68 & 50410.814 & 1.356 & .067 \\
\cline { 2 - 7 } & Within Groups & 5243327.271 & 141 & 37186.718 & & \\
\cline { 2 - 7 } & Total & 8671262.611 & 209 & & & \\
\hline \multirow{5}{*}{ GENDER } & Between Groups & 16.923 & 68 & .249 & & \\
\cline { 2 - 7 } & Within Groups & 33.672 & 141 & .239 & & \\
\cline { 2 - 7 } & Total & 50.595 & 209 & & & \\
\hline
\end{tabular}

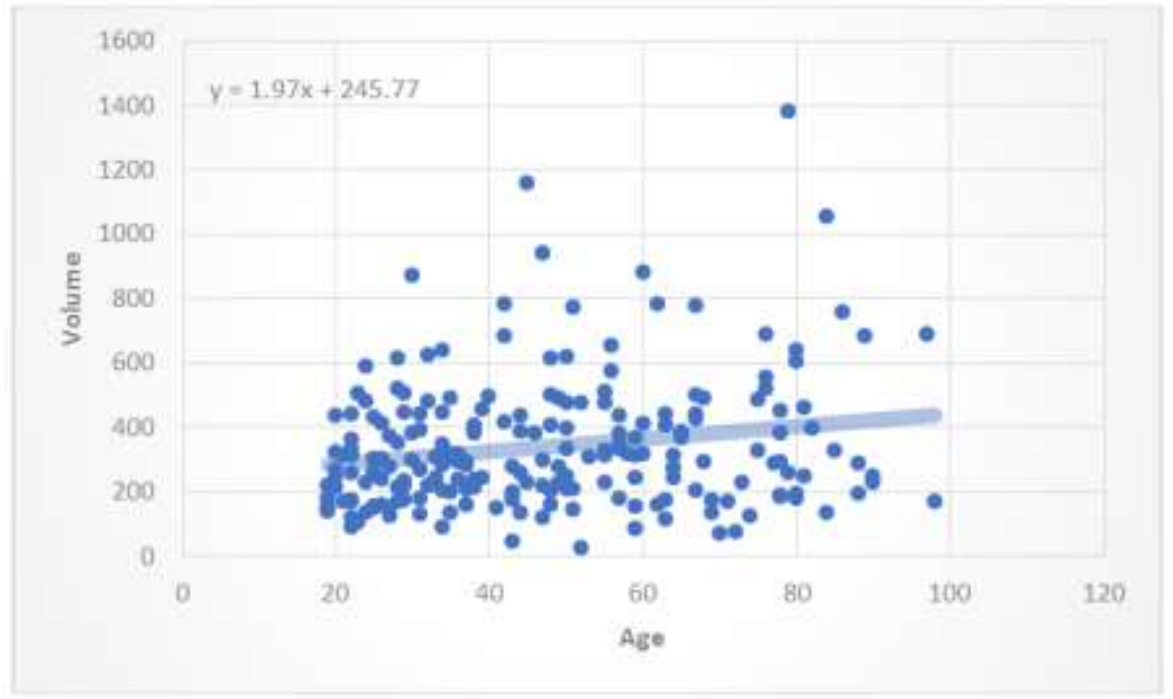

Fig-2: Show correlation between the volume of sella turcica and patients age

\section{DisCUSSIONS}

The mean and standard deviation of various measurements obtained from measuring of Sella turcica, were the mean \pm standard deviation for age was $47.59 \pm$ 20.289 years, length, Width, AP and volume of Sella turcica was $8.07 \pm 2.06 \mathrm{~mm}, 7.408 \pm 1.64 \mathrm{~mm}$, $10.11 \pm 2.08 \mathrm{~mm}$ and $339.52 \pm 203.69 \mathrm{~mm}$ respectively.

Relations between age group with volume of Sella turcica, were the age divided to five group (less than 19 years), (19-25 years), (26-40 years), (41-50 years) and (more than 50 years), the mean \pm standard deviation for patients with age < 19 years was $166.28 \pm 32.41 \mathrm{~mm}, 19-25$ years was $279.46 \pm 133.73$ $\mathrm{mm}$, for age 26-40years, 41-50 years and > 50 years was $317.80 \pm 149.43 \mathrm{~mm}, \quad 363.75 \pm 259.36 \mathrm{~mm}$ and $374.22 \pm 228.66 \mathrm{~mm}$ respectively.

The mean and standard deviation for measurements obtained from males and females are tabulated above Table 3. The mean length of sella turcica for male and female was 8.010 and $8.165 \mathrm{~mm}$, the Width for male was $7.215 \mathrm{~mm}$ and for female 7.692 $\mathrm{mm}$, AP diameter for male 10.050 and for female $10.193 \mathrm{~mm}$, the volume of sella turcica for male was 329.139 and for female $354.781 \mathrm{~mm}$, so there is no difference between male and females. This finding confirmed with [31] reported that no statistically significant difference between Sella turcica diameters and gender. However, the study [32] reported significant different in linear dimension between genders in height and width.

The study found that Sella Turcica gave three unique shapes: the circle shape represent $40.5 \%$ with 85 patients, the ovoid shape $42.4 \%$ with 89 patients while the flat shape $17.1 \%$ with 36 patients, and found ovoid to be the most frequent shape and this result similar [33], for Bangladesh populations, who describe Sella shape with the three common shapes.

There is linear correlation between age of study group and the measured parameters from 19- 99 
years. Analysis of variance test show that there was no significant difference between the Sella measurements, for length and patients age, where the p-value was 0.285 . and for Width, AP and volume the p.value was $0.222,0.128$ and 0.067 respectively, and with gender give a good correlation were the p.value 0.412 and this is not consistent with [34] found a significant correlation between Sella Width and patient ages and this is agreed with [35] were found strong correlation between Sella height and gender.

The correlation between the volume of sella turcica and patients age, where the rate of change of volume increase with increase the patients age with rate 1.97 for each year as shown in Figure-2.

\section{Conclusions}

This study deal with measuring the size and shape of normal Sella turcica and find out three unique shapes; the circle shape represents $40.5 \%$ with 85 patients, the ovoid shape $42.4 \%$ with 89 patients while the flat shape $17.1 \%$ with 36 patients, measurements obtained from measuring of Sella turcica, were the mean \pm standard deviation for age was $47.59 \pm 20.289$ years, length, Width, AP and volume of Sella turcica was $8.07 \pm 2.06 \mathrm{~mm}, 7.408 \pm 1.64 \mathrm{~mm}, 10.11 \pm 2.08 \mathrm{~mm}$ and $339.52 \pm 203.69 \mathrm{~mm}$ respectively. The mean length of sella turcica for male and female was 8.010 and $8.165 \mathrm{~mm}$, the Width for male was $7.215 \mathrm{~mm}$ and for female $7.692 \mathrm{~mm}$, AP diameter for male 10.050 and for female $10.193 \mathrm{~mm}$, the volume of sella turcica for male was 329.139 and for female $354.781 \mathrm{~mm}$, so there is no difference between male and females.

There is linear correlation between age of study group and the measured parameters from 19-99 years. Analysis of variance test show that there was no significant difference between the Sella measurements, for length and patients age, where the p-value was 0.285 and for Width, AP and volume the p. value was 0.222 , 0.128 and 0.067 respectively. CT can be used to assess the Sella turcica, and further studies on how the dimensions of the Sella turcica are interrelated with pathological conditions should be conducted with the use of advanced imaging methods.

\section{REFERENCE}

1. Kjær I. Sella turcica morphology and the pituitary gland - a new contribution to craniofacial diagnostics based on histology and neuroradiology. Eur J Orthod. 2015; 37:28-36.

2. Tekiner H, Acer N, Kelestimur F. Sella turcica: an anatomical, endocrinological, and historical perspective. Pituitary. 2015; 18:575-578.

3. Nielsen BW, Molsted K, Kjær I: Maxillary and sella turcica morphology in newborns with cleft lip and palate. Cleft Palate Craniofac J. 2005; 42:610617.
4. Sundareswaran S, Nipun CA. Bridging the gap: sella turcica in unilateral cleft lip and palate patients. Cleft Palate Craniofac J. 2015; 52:597604.

5. Osman M, Allan JC, Kramer B. A pharyngeal and ectopic hypophysis in a neonate with craniofacial abnormalities: a case report and review of development and structure. Cleft Palate Craniofac J. 2006; 43:117-122.

6. Axelsson S, Storhaug K, Kjaer I. Post-natal size and morphology of the sella turcica in Williams syndrome. Eur J Orthod. 2004; 26:613-621.

7. Bonneville JF, Cattin F, Dietemann JL. Hypothalamic-pituitary region: computed tomography imaging. Baillieres Clin Endocrinol Metab. 1989; 3:35-71.

8. Korayem M, AlKofide E. Size and shape of the sella turcica in subjects with Down syndrome. Orthod Craniofac Res. 2015; 18:43-50.

9. Kucia A, Jankowski T, Siewniak M, JaniszewskaOlszowska J, Grocholewicz K, Szych Z, Wilk G. Sella turcica anomalies on lateral cephalometric radiographs of Polish children. Dentomaxillofacial Radiology. 2014 Dec;43(8):20140165.

10. Alkofide EA. Sella turcica morphology and dimensions in cleft subjects. Cleft Palate Craniofac J. 2008; 45:647-653.

11. Ludlow JB, Ivanovic M. Comparative dosimetry of dental CBCT devices and 64-slice CT for oral and maxillofacial radiology. Oral Surg Oral Med Oral Pathol Oral Radiol Endod. 2008; 106:106114.

12. Pisaneschi M, Kapoor G. Imaging the sella and parasellar region. Neuroimaging Clin N Am. 2005; 15(1):203-19.

13. Teke HY, Duran S, Canturk N, Canturk G. Determination of gender by measuring the size of maxillary sinuses in computerize tomography scans. Surgical Radiologic Anatomy. 2007; 29:913.

14. Mutluer S. Sella Turcica. Childs Nervous System. 2006; 22:333.

15. Chaurasia BD. Human anatomy: Regional and applied, disssection and clinical volume $36^{\text {th }}$ Edition. CBS Publishers an Distributors Pvt Ltd. 2013;46-54.

16. Tadros AA, Zagga AD, Usman JD, Bello A. Tadro's atlas of human anatomy. Amal Printing and Publishing Nigeria limited, Kaduna, Nigeria. 2012; 1(3):36-57.

17. Subhandra DV, Baburao S. Age and sex related morphology and morphometry of sellar region of sphenoid in prenatal and postnatal human cadavers. International Journal Research Development Health. 2013; 1:141-48.

18. Ani S, James J Prasanth SP. Morphology of sella turcica in skeletal class II subjects. Journal of Respiratory Practical Dentology.2015;10:5171.

19. 19. Damman F, Bode A, Heuschmid M, Kopp A, Georg C, Pereira PL, Claussen CD. Multislice CT 
of the paranasal sinuses: First experiences using parameters of radiation dosage. Rofo. 2000; 172(8):701-702.

20. Shahbazian M, Xue D, Hu Y, Cleynenbreuge J, Jacobs R. Spiral computed tomography based maxillary sinus imaging in relation to tooth loss, implant placement and potential grafting procedure. Journal of Oral and Maxillofacial Research. 2010; 1(1):7-10.

21. Newton TH, Potts DG. Radiology of the skull and brain, The Skull Book 1. 1971; 1(1):359-405.

22. Kurcia A, Jankowski T, Siewniak M. Sella turcica anomalies on lateral cephalometric radiographs of Polish children. Dentomaxillofacial Radiology. 2014; 43(8):20140165.

23. Russell BG, Kjaer I. Postnatal structure of sella turcica in down syndrome. American Journal of Medical Genetics. 2008; 87:183-188.

24. Axelsson S, Storhaug K, Kjaer I. A postnatal size and morphology of the sellaturcica in williams syndrome. Europeanjournal of Orthodontics. 2004; 26:613-621.

25. Sinnatamby CS. Last's anatomy: Regional and applied. Edinburgh; Churchill Livingstone. United Kingdom. 2011; 501-504.

26. Kantor ML, Norton LA. Normal radiographic anatomy and common anomalies seen in cephalometric films. American Journal of Orthodontics and Dentofacial Orthopedics. 1987; 91:414-426.

27. Kjær I, Wagner A, Madsen P, Blichfeldt S, Rasmussen K, Russell B. The sella turcica in children with lumbosacral myelomeningocele. European Journal of Orthodontics. 1998; 20:443448.
28. Kjær I, Keeling JW, Fischer Hansen B, Becktor KB. Midline skeletodental morphology in holoprosencephaly. Cleft PalateCraniofacial Journal. 2002; 39:357-363

29. Russell BG, Kjær I. Postnatal structure of the sella turcica in Down syndrome. American Journal of Medical Genetics. 1999; 19:183-188.

30. Kjær I, Hjalgrim H, Russell BG. Cranial and hand skeleton in fragile X syndrome . American Journal of Medical Genetics. 2001; 100:156-161.

31. Sakran AMEA, Khan MA, Altaf FMN, Fragella HEH, Mustafa AYAE, Hijazi MM, Niyazi RA, Tawakul AJ, Malebari AZ, Salem AAA. A morphometric study of the sellaturcica; gender effect. International Journal of Anatomy and Research. 2015; 3:927-34.

32. Chauhan P, Kalra S, Mongia SM, Ali S, Anurag A. Morphometric analysis of sellaturcica in North Indian population: a radiological study. International Journal of Research in Medical Sciences. 2014: 2:521-6.

33. SHAH A, Bashir U, Ilyas T. The shape and size of the sella turcica in skeletal class I, II \& III in patients presenting at Islamic International Dental Hospital, Islamabad. Pakistan oral \& dental journal. 2011 Jun 1;31(1)

34. Kricheff II. The radiologic diagnosis of pituitary adenoma: an overview. Radiology. 1999; 131: 263-265.

35. Haritha PS, Vignesh, K, Arun C. The Size and Morphology of Sella Turcica in Different Skeletal Patterns among South Indian Population: A Lateral Cephalometric Study. JP Journals. 2013: 47(4):266-271. 